\title{
The Effect of Intensive Exercise on Beta-Endorphin and Serum Cortisol Levels in Elite Wrestlers
}

\author{
Mansour Enayatjazi ${ }^{1}$, Saeed Sadeghi Dinani ${ }^{1}$, Seyed Ali Emami Hashemi2 ${ }^{\text {* }}$ \\ 1. Department of Sport Physiology, Faculty of Physical Education, University of Isfahan, Isfahan, Iran. \\ 2. Department of Health and Sport Medicine, Faculty of Physical Education and Sport Science, Kharazmi University, Tehran, Iran.
}

Citation: Enayatjazi M, Sadeghi Dinani S, Emami Hashemi SA. The Effect of Intensive Exercise on Beta-Endorphin and Serum Cortisol Levels in Elite Wrestlers. Physical Treatments. 2015; 5(3):171-176.

Article info:

Received: 09 Apr. 2015

Accepted: 01 Sep. 2015

Keywords:

Beta-endorphin, Serum cortisol, Exercise, Athletes

\begin{abstract}
A B S T R A C T
Purpose: This study aimed to investigate the effect of one intensive training session on the changes of beta-endorphin and serum cortisol levels of elite wrestlers.

Methods: In this quasi-experimental research with one group and pretest-posttest design, 16 elite wrestlers within the age range of 18 to 25 years were purposefully and selected and they voluntarily participated in the research. The subjects performed one session of intensive exercise with the intensity of $85 \%$ to $90 \%$ of maximum heart rate. The blood samples $(5 \mathrm{~mL})$ were collected two times. First it was taken 30 minutes before the exercise and second blood sample was taken immediately after exercise by one expert and two physicians. The data were analyzed by paired-samples t-test using SPSS 17 and $\alpha$ value was set at 0.05 .
\end{abstract}

Results: There was a significant difference between beta-endorphin levels of elite wrestlers before and immediately after the exercise session $(\mathrm{P}=0.024)$. The serum cortisol level also increased significantly during the test $(\mathrm{P}=0.048)$.

Conclusion: According to the findings of the study, beta-endorphin increase can make happy the athletes. Furthermore, the rise of cortisol level can increase the efficiency of immune system, boost the energy, maintain the body balance, and decrease the pain sensation.

\section{Introduction}

H

ormones are chemicals secreted by the endocrine glands in the body fluids and they specially affect the activities of other organs (target organs). The endocrine glands lack secretion ducts and release their hormones directly into the blood and lymph. cises differently. According to various studies and trials, changes of beta-endorphin and plasma cortisol concentrations depend mostly on exercise intensity [1]. Time of exercise is also a decisive factor in these changes. Numerous studies have been done on the effect of exercise on changes of plasma beta-endorphin. Also, there is a relationship between the anterior pituitary hormone in response to exercise and beta-endorphin and cortisol.

Beta-endorphin and cortisol hormones respond to exer-

\section{* Corresponding Author:}

Seyed Ali Emami Hashemi, PhD Candidate

Address: Department of Health and Sport Medicine, Faculty of Physical Education and Sport Science, Kharazmi University, Tehran, Iran.

Phone: +98 (913) 2020532

E-mail:aemami@ut.ac.ir 
A team of researchers reported that secretion of betaendorphin was correlated with ACTH [2].

Although there are many reports indicating that sprint exercises increase the amount of plasma beta-endorphin [3], there are differences between previous study results with regard to sex, training stage, testing protocols, anxiety level, stress, thermoregulation, and taking repeated blood samples [4]. The results of study by Resaee and colleagues indicated that the concentration of opiate peptides, especially beta-endorphin increased during exercise even up to 5 times. Also, according to another research, the beta-endorphin and beta-lipotropic response to exercise in men was much more than that in women. Levels of serum beta-endorphin while doing the aerobic exercise from light to moderate intensity (20\% to $50 \%$ of maximum consumed oxygen) did not change substantially, while the maximum and intensive exercises ( $80 \%$ of consumed oxygen) led to a significant increase in beta-endorphin levels. Investigations revealed that beta-endorphin responds very quickly because the maximum level exercises lead to significant increase of beta-endorphin in 30 seconds [5]. Evidence suggests that if the exercises are done in a wrong way and too intensively, it will lead to symptoms of depression and stress in athletes [6].

According to studies, doing exercise is the primary driver for the release of beta-endorphin. Beta-endorphin secretion depends on both volume and intensity of aerobic exercises. The effect of sports intensity on the betaendorphin and cortisol is associated with physiological adaptation of competitors [7]. In some studies, betaendorphin and cortisol responses were compared before and after exercise. They found that a positive correlation exists between anaerobic exercises and beta-endorphin levels. These findings support the effect of exercise intensity on endogenous opiate system receptors.

In contrast to other studies, the present study considered the effects of an intensive exercise session on the variation of serum cortisol and beta-endorphin of elite wrestlers. Setting of measurements (serum, plasma, saliva, or cerebrospinal fluid) is another common problem for measuring beta-endorphin. However, it is easier to replace the cerebrospinal fluid with serial blood samples. It is important to remember that there is a positive correlation between corticotrophin and releasing the beta-endorphin as well as variable correlation with cortisol, and there may be some direct effects on betaendorphin levels [3]. Many wrestlers feel euphoric after exercise because of endorphin release, which results in a morphine-like feelings.
A few studies have shown that physical or psychological stress can have serious physiological effects through hormonal changes and conversely joy and happiness can have beneficial effects on all body systems, especially the cardiovascular system [8]. Numerous studies have investigated the impact of exercise on beta-endorphin and cortisol levels and most of them have confirmed beta-endorphin and cortisol increase in all exercises. However, there are possible changes in the secretion of these hormones in different sports depending on various protocols of exercises and environments. Because the measurement of beta-endorphin in athletes was rarely done, the present study was designed to evaluate the effect of one wrestling training session on cortisol and beta-endorphin changes of elite wrestlers and determine whether one training session of wrestling like other speed trainings could increase their beta-endorphin and cortisol levels. Also, whether their bodies have adapted to the exercise and increased beta-endorphin and cortisol levels or whether these athletes are experiencing overtraining, given that all these wrestlers were training 2 hours a day. Because of the above unanswered questions, we decided to study the response of beta-endorphin and cortisol of elite athletes of this sport in a special training session.

\section{Materials and Methods}

In this quasi-experimental research with one group and pretest-posttest design, 16 elite wrestlers of Isfahan, with an average (SD) age of 23.53(3.41) years were purposefully selected and they voluntarily participated in the study. Subjects performed their special training at least 6 times a week; each session lasted 2-2.5 hours. The inclusion criteria included being in perfect physical health, having no history of mental illness and hormonal disorders, having sports experience, not using medicines, supplements, and drugs such as cigarettes and hookah.

After explaining the research process, the consent forms and the questionnaire of public profile and history of the disease were given to subjects. Then, they were asked to adopt a normal sleep pattern (at least 8 hours of a day), normal daily activity patterns, and normal diet. They were also asked to refrain from intense physical activity, medication, food supplements, coffee consumption, using tobacco and cocoa which affect immune system 48 hours before the test and after collecting blood samples.

A week before doing the test, subjects' physical characteristics such as weight, height, and body mass index were measured and recorded. To determine the weight, 
a digital scale (made in Germany), with a stadiometer with precision of $0.5 \mathrm{~cm}$ and scale precision of $0.01 \mathrm{~kg}$ was used. For measuring body weight of the subjects, they must stand on the scale wearing a swim suit to do the most accurate measurement. The subjects' weight was recorded in kilograms. To measure the height, a tape measure fixed on the wall and a ruler was used. The heights of the subjects were recorded in centimeter. Body mass index (BMI) was assessed and recorded by calculating the ratio of weight $(\mathrm{kg})$ by the square of height (m).

Then, the subjects participated in a special training session at $85 \%-90 \%$ of maximum heart rate (maximum reserved heart rate $=$ resting heart rate-maximum heart rate) at a temperature of $22^{\circ} \mathrm{C}$ and a relative humidity of $35 \%$ for 90 minutes. Basic training program included warm up, special training, and recovery. Blood samples $(5 \mathrm{~mL})$ were taken from all subjects by three sampling specialist (an expert and two physicians) after 12 hours of fasting between $8 \mathrm{AM}$ to $10 \mathrm{AM}$ for determining the levels of beta-endorphin and serum cortisol. The first series of blood samples were collected 30 minutes before the beginning of training and the second series of blood samples were collected immediately after the training. The collected blood samples in both time points were kept in 2 series of special pipes (to save in case of broken pipes). To prevent hemolysis of the blood serum, they were immediately separated by Hettich refrigerated centrifuges (made in Germany) at a temperature of $4^{\circ} \mathrm{C}$ for 10 minutes at $3000 \mathrm{rpm}$ and were poured into separated microtubes. After each stage of the sampling and putting samples on dry ice, 2 sets of each subject were determined and frozen at $-70^{\circ} \mathrm{C}$ in lab freezers for several weeks to be tested on later.

We used Elisa kit s1240 b-endorphin human free extraction (without extraction), (Bachern Co, USA) to measure beta-endorphin and cortisol kits (IBL Co, Germany) to measure cortisol level [9]. ELISA was used to determine the concentration of hormones (CortisolELISA kit range [50-230 ng/mL] between 8-10 AM). It should be noted that to reduce the effect of circadian rhythm all samples were collected at the same time and day (8 to10 AM).

After data collection and confirmation of its normal distribution with Kolmogorov-Smirnov test, pairedsamples t-test was used to compare the changes betaendorphin and cortisol level before and after the training session. All data analysis was done by SPSS version 17 and the significance level was set at 0.05 .

\section{Results}

Table 1 shows the physical and physiological characteristics of the wrestlers. Table 2 shows the results of paired-samples t-test on variables of $\beta$-endorphins and cortisol of elite wrestlers. There is a significant difference between the average values of the $\beta$-endorphin in the wrestlers before and after the training $(\mathrm{P}<0.05)$. There is also a significant difference between the average values of serum cortisol of the wrestlers before and after the training $(\mathrm{P}<0.05)$.

In Figure 1, the general trend of changes in beta-endorphin of wrestlers has been displayed during different stages of test which indicates a significant difference

Table 1. Physical and physiological characteristics of the wrestlers.

\begin{tabular}{|c|c|c|c|c|c|}
\hline Variables & $\begin{array}{l}\text { Maximum consumed } \\
\text { oxygen } \mathrm{mL} /(\text { kg.min) }\end{array}$ & BMI $\left(\mathrm{kg} / \mathrm{m}^{2}\right)$ & Height $(\mathrm{cm})$ & Weight (kg) & Age (y) \\
\hline Mean $\pm S D$ & $55.27 \pm 4.56$ & $20.99 \pm 1.62$ & $182.21 \pm 5.22$ & $69.78 \pm 6.86$ & $23.53 \pm 3.41$ \\
\hline
\end{tabular}

Table 2. The results of paired-samples t-test on variables of beta-endorphins and cortisol levels of elite wrestlers.

\begin{tabular}{cccc}
\hline Variable & Cortisol $(\mathrm{ng} / \mathrm{mL})$ & Beta-endorphin $(\mathrm{ng} / \mathrm{mL})$ \\
\hline Sampling stages & $\begin{array}{c}\text { Immediately after } \\
\text { training }\end{array}$ & $\begin{array}{c}\text { Before training } \\
\text { Before training }\end{array}$ & $\begin{array}{c}\text { Immediately after } \\
\text { training }\end{array}$ \\
\hline Mean \pm SD & $207.09 \pm 40.50$ & $180.06 \pm 26.1$ & $4.82 \pm 3.69$ \\
Sig. & $\mathrm{P}=0.048$ & $\mathrm{P}=0.024$ \\
t-test & 2.49 & 2.761 \\
\hline
\end{tabular}




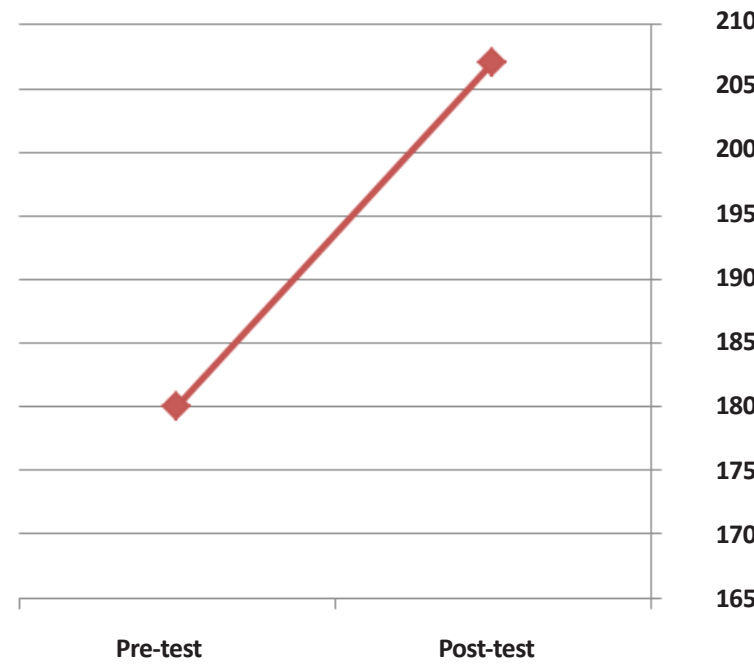

PHYSICAL TREA TMENTS

Figure 1. The linear chart of the serum cortisol.

before and after the training (30 minutes before training, and immediately after training) $(\mathrm{P}<0.05)$. The findings of Figure 2 show that the average sampling of serum cortisol of wrestlers is significantly different in two time periods $(\mathrm{P}<0.05)$.

\section{Discussion}

According to the study results, the amount of betaendorphin significantly increased after a special training session. This change was about twice, previous researches have also experienced an increase of betaendorphin up to five times proportional to the increase in the volume of exercise [9]. Exercise duration greatly affects releasing beta-endorphin [10]. The cycle of betaendorphin secretion is low while the person is inactive which was consistent with this study; i.e. by doing activity, beta-endorphin secretion increased [11].

Park and Yoon in their research showed a significant increase in the amount of beta-endorphin while doing activities with the intensity of $60 \%$ to $80 \%$ of maximum used oxygen consumption and 60 minutes after cessation of activity it returned to normal level [12]. Duration of exercise also has a big impact on the release of betaendorphin in skiers [10]. The levels of beta-endorphin in skiers who skied $150 \mathrm{~km}$ in a week increases more than skiers who skied $20 \mathrm{~km}$ in a week. The athletes of this study practiced their own special sport almost for 2 hours a day and this could be the reason for the significant increase in beta-endorphin [3]. There is a positive correlation between the exercise volume and increased levels of beta-endorphins in people who exercise on an ergometer bicycle [13].

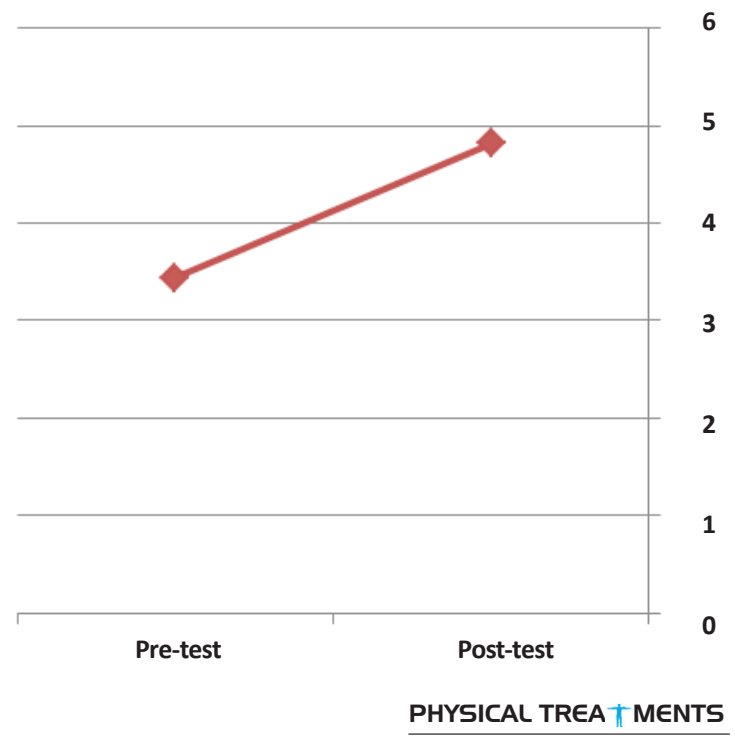

Figure 2. The linear chart of the beta-endorphin

In this study, there was a significant difference between the serum cortisol levels of wrestlers before and after a professional and intensive wrestling training session $(\mathrm{P}<0.05)$. Anthony and colleagues (2006) showed that doing the aerobic exercise with the intensity of more than $50 \%$ of $\mathrm{VO}_{2}$ max could have a special effect on beta-endorphin level [14]. Sutton and colleagues (1990) reported that there was a chronic increase in blood cortisol in professional runners' blood serum that used to exercise in high levels and exacerbated, especially before running [15]. When body is compatible with the stresses of mild exercises, it prepares gradually to stand the other stresses such as pain and emotional stimuli and this could be the reason for significant increase in cortisol levels. The data from the tests indicate the interaction between anterior pituitary hormones of the nervous-immune system and sport while doing both physical activity and intensive physical exercise [16].

HindMarsh and colleagues (1989) in their studies have reported the increase in beta-endorphin and cortisol secretion in people under sports stress [17]. Numerous studies have focused on the effects of exercise on plasma beta-endorphin and concluded that exercise is a factor in rising serum beta-endorphin [18]. In general, the results showed that there was a significant difference between the levels of beta-endorphins and serum cortisol of wrestlers before and immediately after exercise. For future research we suggest that more blood samples be taken in several time points after the test to determine the stability of changes in different times after the test.

The results showed that there was a significant difference in hormone levels of serum cortisol and beta endor- 
phin before exercise and immediately after one session of intensive wrestling exercise. According to the findings, these trainings increase beta-endorphin and serum cortisol level. The rise in beta-endorphin hormone can release endorphins which can increase the happiness of athletes. Therefore, this effect can enhance the motivation and perseverance of athletes in intolerable trainings. On the other hand, cortisol increase can enhance the efficiency of immune system, boost energy, maintain the body balance, and decrease the pain sensation.

\section{Acknowledgements}

The current research hasn't received any financial support.

\section{Conflict of Interests}

The authors declared no conflict of interests.

\section{Reference}

[1] Farrell PA, Gates WK, Maksud MG, Morgan WP. Increases in plasma beta-endorphin/beta-lipotropin immunoreactivity after treadmill running in humans. Journal of Applied Physiology. 1982; 52(5):1245-249.

[2] de Meirleir K, Naaktgeboren N, Van Steirteghem A, Gorus F, Olbrecht J, Block P. Beta-endorphin and ACTH levels in peripheral blood during and after aerobic and anaerobic exercise. European Journal of Applied Physiology and Occupational Physiology. 1986; 55(1):5-8.

[3] Bender T, Nagy G, Barna I, Tefner I, Kádas É, Géher P. The effect of physical therapy on beta-endorphin levels. European Journal of Applied Physiology and Occupational Physiology. 2007; 100(4):371-82.

[4] Kraemer RR, Kilgore JL, Kraemer GR, Castracane VD. Growth hormone, IGF-I, and testosterone responses to resistive exercise. Medicine and Science in Sports and Exercise. 1992; 24(12):1346-352.

[5] Rasaee MG, Gaeeni AA, Nazem F. [Hormone compliance and exercise (Persian)]. 1 $^{\text {st }}$ ed. Tehran: University of Tarbiyat Modaress; 2004

[6] Kraemer RR, Blair S, Kraemer GR, Castracane VD. Effects of treadmill running on plasma beta-endorphin, corticotropin, and cortisol levels in male and female 10K runners. European Journal of Applied Physiology and Occupational Physiology. 1989; 58(8):845-51.

[7] Fazio E, Medica P, Aronica V, Grasso L, Ferlazzo A. Circulating beta-endorphin, adrenocorticotrophic hormone and cortisol levels of stallions before and after short road transport: stress effect of different distances. Acta Veterinaria Scandinavica. 2008; 50(1):6. doi: 10.1186/1751-0147-50-6
[8] Boecker H, Sprenger T, Spilker ME, Henriksen G, Koppenhoefer M, Wagner KJ, et al. The runners high: opioidergic mechanisms in the human brain. Cerebral Cortex. 2008 18(11):2523-531.

[9] Nosrat Abadi M, Malek-Nia N. [Comparativ measurements of plasma beta-endorphins in normal subjects and drug addicts (Persian)]. Paper presented at: The 1 Iranian Congress of Biochemistry; 1991 June 24; Zahedan, Iran

[10] Petraglia F, Modena AB, Comitini G, Scazzina D, Facchinetti F, Fiaschetti D, et al. Plasma beta-endorphin and beta-lipotropin levels increase in well trained athletes after competition and non competitive exercise. Journal of Endocrinological Investigation. 1990; 13(1):19-23.

[11] Maisel AS, Harris T, Rearden CA, Michel MC. Beta-adrenergic receptors in lymphocyte subsets after exercise. Alterations in normal individuals and patients with congestive heart failure. Circulation. 1990; 82(6):2003-010

[12] Yoon JR, Park SC. Exercise intensity-related responses of B-endorphin, ACTH, and cortisol. Korean Journal of Sport Science. 1991; 3:21-32.

[13] Schwarz L, Kindermann W. Beta-endorphin, adrenocorticotropic hormone, cortisol and catecholamines during aerobic and anaerobic exercise. European Journal of Applied Physiology and Occupational Physiology. 1990; 61(3-4):165-71.

[14] Hackney AC. Exercise as a stressor to the human neuroendocrine system. Medicina (Kaunas). 2006; 42(10):122-34.

[15] Sutton JR, Vell F, Harber VJ. Hormonal adaptation to physical activity. In: Bouchard, C, editor. Exercise, Fitness, and Health: A Consensus of Current Knowledge. Champaign: Human Kinetics Books; 1990, p. 217-65.

[16] Farzanaki P, Azarbayjani MA, Rasaee MJ, Jourkesh M, Ostojic SM, Stannard S. Salivary immunoglobulin A and cortisol response to training in young elite femaile gymnasts. Brazilian Journal of Biomotricity. 2008; 2(4):252-58

[17] Hindmarsh KW, Tan L, Sankaran K, Laxdal VA. Clinical investigation diurnal rhythms of cortisol, ATCH, and Pendophin levels in neonates and adults. Western Journal of Medicine. 1989; 151(2):153-56.

[18] Tagashira S, Yamaguchi K, Matsunaga T, Toad K, Hayashi Y. Salivary preallikrein output during the ranger traininginduced stress. Stress and Health. 2004; 20(5):249-53. 
